\title{
Does Perceived Ease of Use Mitigate Computer Anxiety and Stimulate Self-regulated Learning for Pre-Service Teacher Students?
}

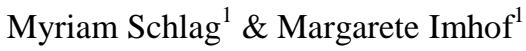 \\ ${ }^{1}$ Educational Psychology, Johannes Gutenberg University, Mainz, Germany \\ Correspondence: Myriam Schlag, Educational Psychology, Johannes Gutenberg University, Mainz, Germany.
}

Received: May 19, 2017

Accepted: June 6, 2017

Online Published: June 12, 2017

doi:10.5430/ijhe.v6n3p154

URL: https://doi.org/10.5430/ijhe.v6n3p154

\begin{abstract}
The aim of this study is to contribute to a better understanding of challenges and factors which influence learning efficiency with electronic-portfolios. Based on the Technology Acceptance Model (TAM; Davis, Bagozzi, \& Warshaw, 1989) we analyzed external variables (e.g., computer-anxiety) that influence technology acceptance and the actual system use in form of self-regulated learning. Additionally we included computer related attitudes and correlated them with external variables as well as measures of self-regulated learning. To foster learning efficacy with electronic portfolios the program Microsoft OneNote was used. A group of $N=32$ preservice teachers worked on an electronic-portfolio in OneNote for 14 weeks.

Results showed that computer-anxiety and the challenge of working with an electronic portfolio decreased over time. The more the computer was rated as a useful tool for learning and teaching, the less computer-anxiety, the more challenge and interest and better mood students reported. In contrast the more the computer was seen as uninfluential tool for working and learning, the more computer anxiety, hopelessness, anxiety and less positive mood, interest and joy to work on the electronic-portfolio has been reported. So, students' computer related attitudes should be considered when working with an electronic-portfolio to better tailor instruction to learner needs.
\end{abstract}

Keywords: Electronic portfolios, Pre-service teachers, Computer anxiety, Self-regulated learning, Technology Acceptance Model

\section{Introduction: Using portfolios in Teacher Education Programs}

Using portfolios in teacher education courses has been found to foster reflexive competences of pre-service teachers and in the context of teacher training (Darling-Hammond \& Snyder, 2000; Imhof \& Picard, 2009; Rijdt, Tiquet, Dochy, \& Devolder, 2006, Zeichner \& Wray, 2001). While portfolio can take on a variety of forms, the core of the portfolio methods is that it is a personalized collection of documents and artifacts which demonstrate learning and reflect a learner's growth process over time. From time to time and at critical steps in the learning process, the teacher asks learners to evaluate the collected documents, e.g., readings, papers, notes, and feedback, and to write a reflection on how and what he or she has learned and which future directions have developed. The assignment to keep a portfolio to stimulate and support learning processes has shown positive effects (Darling-Hammond \& Snyder, 2000), in particular in the context of subjects and courses which put emphasis on the development of reflective skills and for which the process of learning is as much a part of the course objectives as the content itself (Mansvelder-Longayroux, Beijaard, \& Verloop, 2007).

Considering the amount of text which needs to be written, stored, and organized within a portfolio, it is not too far-fetched to think of using an electronic device to administrate the documents which are supposed to go into a portfolio. However, when it comes to using computers as a core component of a learning scenario, it is critical to realize that using an electronic portfolio does not only change the medium for recording (Kimball, 2005). Writing with a pen has been contrasted with using a keyboard in terms of depth of processing (Mueller \& Oppenheimer, 2014). When using electronic devices to support student learning, teachers both face specific challenges and issues such as anxiety, and negative attitudes, and low self-efficacy towards using technology (Cai, Fan \& Du, 2017) might create barriers to successful learning. The aim of this study is to contribute to a better understanding of these challenges and the factors which influence learning efficiency with electronic portfolios. 


\section{Literature Review on the Design and Use of Electronic Portfolios}

\subsection{Design of an Electronic Portfolio}

Portfolios as well as electronic portfolios are often used in teacher education programs to foster students' competencies (Darling-Hammond \& Snyder, 2000; Zeichner \& Wray, 2001). For the current study, we designed an electronic portfolio as a structured collection of learning digital material, including readings, personal notes, observation protocols, reflective texts, to document the learning process of the students. Students are provided with a roughly pre-structured electronic folder, a template, which contains a variety of tasks and learning material. During the course of the semester, students further develop their portfolio template to present their individual progress and to suit their personal learning style. Students can choose how much time they want to spend on which task and what kind of material and information they need, what they would want to add and how often they go back to revise and review.

\subsection{Challenges and Chances of Using an Electronic Portfolio: Usability and Metacognition}

To develop an electronic portfolio with students who are new in the field of computer-assisted learning, it often entails that students need an introduction to new software. This can take valuable time in the course and students might be tired of learning another software, while course content, learning and studying course material seem to drift away from the focus of attention. Still, teachers insist on using electronic components in a learning environment for the added value that comes from studying with an electronic portfolio (Driessen, Muijtjens, van Tartwijk, \& van der Vleuten, 2007; Lynch \& Purnawarman, 2004). When learners organize their learning material within an electronic portfolio they are likely to not only increase their self-regulated learning skills (Alexiou \& Paraskeva, 2010; Cheng \& Chau, 2013), but also to learn how to draw connections between distant learning events (Cambridge, 2008; Driessen et al., 2007). Documents in an electronic form can be easily shared with and commented by others (Driessen et al., 2007), such as peers and teachers. In addition, using electronic devices and gaining experience in handling computer software is an important prerequisite for using computers skillfully in a professional context (Kimball, 2005). As a consequence, if using computers for learning is considered to be more than something "nice to have," learners should acquire the pertaining expertise, in particular, when they are going to be teachers for the next generation of students (Aldunate \& Nussbaum, 2013).

The focus of this study is on how the technical problems and challenges of handling a computer software for the management of an electronic portfolio could be minimized, so that the electronic component in the learning environment is a helpful tool for and not an obstacle to learning. The objective of the learning environment is that content and process of learning remain clearly in the focus of the activities, and the added-value of the electronic portfolio can still be brought to bear.

\subsection{Technology Acceptance as a Prerequisite for Computer Assisted Learning}

What we know about the factors, which influence the acceptance of a technical innovation like an electronic portfolio is summarized in the Technology Acceptance Model (TAM; see Figure 1) by Davis, Bagozzi, and Warshaw (1989). TAM is based on the theory of reasoned action (Ajzen \& Fishbein, 1980). Core of the TAM is perceived usefulness and perceived ease of use (Figure 1). Whereas perceived usefulness is "the prospective user's subjective probability that using a specific application system will increase his or her job performance within an organizational context" (Davis et al., 1989, p. 985), perceived ease of use is defined as "the prospective user [expectation that] the target system be free of effort" (Davis et al., 1989, p. 985). Both, perceived usefulness and perceived ease of use, are influenced by external variables and, in turn, influence attitudes toward using. Additionally perceived ease of use not only directly influences attitudes toward using but also indirectly via perceived usefulness. Therefore, attitudes toward using as well as perceived usefulness have an impact on the behavioral intention to use, which in turn influence the actual system use. 


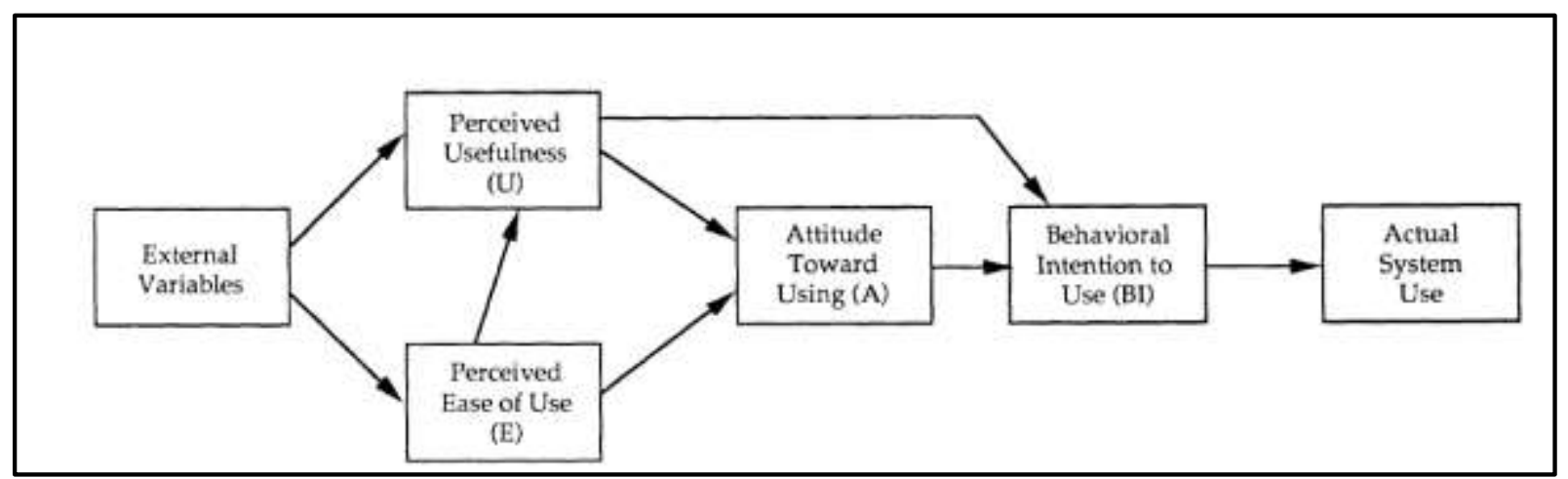

Figure 1. Technology Acceptance Model (TAM) by Davis et al. (1989)

To transfer the TAM to our use of an electronic portfolio in higher education, we will concentrate on different parts of the model. Computer related attitudes or attitude toward using come into play when learners work with an electronic portfolio. Additionally, external variables will be considered. However, the focus of the following study will be on the perceived ease of use of a computer system for electronic portfolios.

\subsubsection{External Variables: Computer Anxiety and Additional External Variables}

Empirical evidence shows that computer anxiety is in the way of learning how to use electronic learning environments efficiently (Celik \& Yesilyurt, 2013; Erice \& Ertas, 2011; Moran, Hawkes, \& El Gayar, 2010; Shapka $\&$ Ferrari, 2003). Computer anxiety is defined as stable disposition (trait) including cognitive and affective components (Richter, Naumann, \& Horz, 2010). Richter, Naumann, and Groeben (2000) emphasize that computer attitudes and computer anxiety are not always clearly distinguished. Concerning the development of computer anxiety while working with a new technology, Venkatesh and Bala (2008) argue that the impact of computer anxiety on perceived ease of use will decline with increasing experience. Because with increasing experience "users will develop accurate perception of effort required to complete specific tasks (i.e., objective usability) and discover aspects of a system that lead to enjoyment (or lack of thereof)" (Venkatesh \& Bala, 2008, p. 282). Similar results have been reported by Richter, Naumann and Horz (2010) who found significantly negative correlations between actual use (e.g., years of computer usage; time of computer usage) and computer anxiety.

The term external variables was specified by Venkatesh and Bala (2008) in later versions of the TAM. In addition to computer anxiety, other variables come into play, e.g., computer self-efficacy, perception of external control and computer playfulness, influencing perceived ease of use. But not only anchor variables also adjustments (perceived enjoyment, objective usability) are connected to perceived ease of use.

The external variables do not only influence perceived ease of use but also perceived usefulness in the TAM. These variables were specified by Venkatesh and Davis (2000), to include subjective norm, image, job relevance, output quality, result demonstrability. Next to voluntariness as a moderator for subjective norms, experience moderates the following external variables: subjective norms, computer anxiety, computer playfulness, perceived enjoyment and objective usability (Venkatesh \& Bala, 2008).

\subsubsection{Attitude towards Using: Computer related Attitudes}

According to the TAM attitude toward using an electronic portfolio according to the TAM can contain specific attitudes toward portfolios but in case of an electronic portfolio also computer related attitudes. Computer related attitudes might be even more important when students have never worked before on an electronic portfolio.

In the same vein, computer related beliefs and attitudes may hinder learners to fully use the benefits which could be derived from using electronic tools for learning (Shapka \& Ferrari, 2003; Teo, Lee, \& Chai, 2008). Following the definition of Richter et al. (2000) computer related attitudes can be defined as cognition-based attitudes which "[...] consist of the structured set of evaluate beliefs which a person holds toward the computer" (p. 476). These attitudes are distinguished from affect based attitudes, emotional dispositions and behavioral intention (Richter et al., 2000). 


\subsubsection{Actual System Use: Using Portfolio to Stimulate Self-regulated Learning}

Since the actual system use of, e.g., an electronic portfolio, is not always optional in learning settings like university or school, it cannot be measured. Therefore characteristics of usage can be used to describe the learning process with the electronic portfolio. These characteristics of usage can be found in variables for self-regulated learning.

"Self-regulation refers to self-generated thoughts, feelings, and actions that are planned and cyclically adapted to the attainment of personal goals" (Zimmerman, 2005, p. 14). According to Zimmerman (2002), self-regulated learning can be divided into three phases: forethought phase, performance phase and self-reflection phase. The forethought phase includes task analysis and self-motivational beliefs like self-efficacy. The performance phase contains self-control as well as self-observation. Self-judgement and self-reaction belong to the third, the self-reflection phase (Zimmerman, 2002). So, what is required of a self-regulated learner? Besides knowledge and skills the learner needs to pluck up motivation, self-discipline, and willpower (Hoy \& Schönpflug, 2008) to initiate learning, and to sustain effort investment. Schmitz and Wiese (1999) add aspects of learning regulation like learning strategies, study time and extern as well as intern learning situations. The internal learning situation includes the current motivation and current learning relevant emotions like test anxiety and mood. External learning situations are stressors like job related commitments (Schmitz \& Wiese, 1999). To summarize, learning and investing self-regulation competences is required and enforced when students work on their personal electronic portfolio in course. Self-regulated learning can be operationalized by measuring mood, self-control and current motivation that function as characteristics of usage.

The connection between electronic portfolios and self-regulated learning was analyzed by Alexiou and Paraskeva (2013). In a university course (computer science) students created their own electronic portfolio to develop their professional career. Results from a pre- post measure showed that intrinsic and extrinsic motivation as well as self-efficacy and task value significantly increased after creating a portfolio. Cheng and Chau (2013) found positive correlations between self-regulated learning abilities (higher order cognitive skills, metacognitive control strategies, collaborative learning) and achievement as a result of creating an electronic portfolio. Undergraduate students kept the electronic portfolios over three months in an English language enhancement program. These studies support the assumption that the electronic portfolio process is intertwined with self-regulated learning, but it remains unclear how computer related attitudes are connected to self-regulated learning in the electronic portfolio process.

In sum, we have evidence that computer assisted learning, on the one hand, can increase learning and foster skill development and, on the other hand, can induce anxiety and reservations in students and thus be in the way of learning. Therefore, the issue needs to be resolved, how pertaining barriers can be determined and removed to make learning with computers accessible and useful. So, we implemented an easy-to-use-system to create an electronic portfolio and investigate the following question: How do preservice teachers' self-regulation and computer-anxiety develop while working with an electronic portfolio in an easy-to-use-system for one semester?

From this question we derived the following hypotheses concerning computer anxiety and self-regulated learning.

Based on the assumption by Venkatesh and Bala (2008) as well as Richter et al. (2010) that computer anxiety will decline with increasing experience, we expect the same for students working with an electronic portfolio over one semester.

Hypothesis 1: Computer-anxiety will decrease while working on an electronic portfolio in an easy-to-use-system over one semester.

According to Alexiou and Paraskeva (2013) we expect the measures of self- regulated learning will increase while working with an electronic portfolio over one semester.

Hypothesis 2: Measures of self-regulated learning will increase across one semester working with an electronic portfolio.

Using the TAM to systemize influences on technology acceptance, we investigate the effects of the actual use of a system and by external variables. For the case of computer-anxiety and computer related attitudes, Richter et al. (2000) found positive a correlation between skills in security of using the computer and a positive valence in the attitude towards the computer - no matter if the use concerning communication and entertainment or learning and working. The opposite effect was found in connection with a negative valence in attitude towards the computer. Therefore we conclude the following hypotheses:

Hypothesis 3: Computer-anxiety correlates negatively with positive valence in the attitude towards the computer.

Hypothesis 4: Computer-anxiety correlates positively with negative valence in the attitude towards the computer. 
New in this study will be the aspect of connecting computer relates attitudes with characteristics of usage and external variables, except computer anxiety. Therefore we ask the following research questions:

Research Question 1: Do computer relates attitudes correlate with external variables?

Research Question 2: Do computer related attitudes correlate with characteristics of usage?

\section{Method}

\subsection{The Portfolio Scenario}

To accommodate the issues of accessibility and practicability, we looked for software which met the following criteria: It should share features and functions of other software students are familiar with to encourage them to explore the options; it should cater to both beginners with easy-to-use functions and to advanced users which look for more complex applications. For these reasons, we decided to use Microsoft OneNote to create an electronic portfolio in a university course. Students should be able to use it right away, because OneNote features comprise many functions which students are likely to know from other Microsoft applications. Since OneNote is not specifically designed to serve as an electronic portfolio but rather for electronic notetaking (Reimer, Brimhall, Cao, \& O'Reilly, 2009), we also look at the more general uses of the program. When pre-service teachers learn to use the program to organize their learning, they might acquire skills which they can use for their self-organization and in their prospective classrooms.

The electronic portfolio in this study included a basic supply of digital course materials, e.g., PowerPoint slides presented in the course, exercises used in class, reflection tasks and a summary of group assignments and discussions. The general idea was that the collection of tasks and material in the electronic portfolio in OneNote should activate all learners during class-time and between sessions. The teacher checked in on the portfolio entries and the feedback for every single student could be managed via a learning platform into which the portfolios had been uploaded.

\subsection{Participants}

According to the goal of the study to explore pre-service teachers' development when creating an electronic portfolio with OneNote, data has been collected from a course only attended by pre-service teachers. Participants were German pre-service teachers enrolled in two sections of the same teacher education course with an enrollment of 30 students each. Out of the course with two sections $N=32$ students (age: $M=22.83, S D=2.34 ; 50 \%$ female, $53 \%$ in the $5^{\text {th }}$ semester, different teaching subjects, pre-service teachers for high-school) completed the three online questionnaires during the semester. Both sections were conducted by the same instructor and took place in a German university. The purpose of the course was test construction for student teachers as a part of their educational psychology curriculum.

\subsection{Design}

Students were randomly assigned to the OneNote courses because this course format was new and the students did not know at the time of registration that the course would require them to work with the program. There were more than 10 other sections of the same course but without OneNote. Data of the two courses were collected with an online questionnaire at three different times during the semester. Out of the 14 lessons (one each week), data was collected at the second, the eighth and the fourteenth lesson. Students completed the online questionnaire during class time. Each online questionnaire took about thirty minutes. Participation was anonymous, voluntary and totally unrelated to any performance assessment and course credits. The three questionnaires were matched by a personal code each student created.

\subsection{Procedure of Courses with OneNote}

In the first class meeting, the handling of the OneNote program was introduced to the students. The course took place in a computer pool at the university. Student worked individually at computers with the same pre-structured version of OneNote. The first nine lessons had the same setting: Each started with a revision of and a feedback to the exercises and assignments which had been completed the week before. After this, the instructor presented a new topic to the students. At the end of each lesson, students received a new OneNote flag containing a new set of slides and tasks concerning the presented topic. Students worked individually on tasks in their OneNote portfolio for about 30 minutes. After working with the electronic portfolio students had to upload their OneNote flag of the lesson to a learning platform and received course credit for working on their OneNote portfolio. In the second part of the semester, students worked in groups for two lessons and created an OneNote flag on a specific course topic (e.g., dyscalculia or ADHD). After sharing the OneNote flag with the rest of the course via the learning platform of the university students discussed their topic. 


\subsection{Measures and Instruments}

Data were collected with online questionnaires. Each study questionnaire started with demographic data including age, current semester, gender and subjects. All other measures were selected in line with modified TAM as will be specified in the following sections.

\subsubsection{External Variables}

Computer Anxiety. A scale by Richter et al. (2010) to assess computer anxiety (COMA) was included at all three times of measurement. The scale includes 8 items (sample item: "I feel confident when dealing with a computer", respondent scale $1=I$ strongly disagree to $5=I$ strongly agree). Richter et al. (2010) present the COMA-scale as reliable (Cronbach's alpha .88) and valid.

Interest regarding content. Interest regarding content of the course was measured only by one item ("Is the topic "normal and exceptional learning processes" interesting for you at first glance?" responding scale $1=$ strongly disagree to $5=$ strongly agree) at the beginning of the course.

Other external variables. At the end of the course (third time of measurement) the following external variables were measured related to the electronic portfolio. The responding scale of each item reached from $1=$ strongly disagree to $5=$ strongly agree. At first, students were asked about their perceived enjoyment ("Using the electronic portfolio in OneNote was fun to me."). The next items included image ("I would recommend the electronic portfolio in OneNote to other students attending the course."), result demonstrability ("I think that I can use exercises or materials out of the electronic portfolio in OneNote again later."), job relevance ("I like to work with an electronic portfolio in OneNote in future courses."; "The aim of the electronic portfolio in OneNote is clear to me.") and output quality ("The instructions and questions in the electronic portfolio in OneNote helped me to understand the content of the course").

\subsubsection{Attitudes towards Using: Computer related Attitudes}

To measure the computer related attitudes a scale by Richter et al. (2010) was used containing 38 items. The scale included eight attitude subscales concerning the evaluative perspective on computer technology (personal experience vs. consequences for society). From the first subscale only the scale personal experience was included, otherwise the questionnaire would have been too long. Further subscales are domains of computer use (learning and work vs. entertainment and communication) and valence (positive vs. negative). A sample item from the subscale personal experience/learning and work/positive: "To me a computer is a useful work equipment." responding scale $5=$ strongly agree to $1=$ strongly disagree. The authors report the scale as reliable (Cronbach's alpha between .78 and .85) and valid (Richter et al., 2010).

\subsubsection{Characteristics of Usage: Measuring Self-regulation}

To measure the self-regulated learning the following three scales have been used at all three points of measurement.

Questionnaire to assess current motivation in learning situations. The scale Momentarily Available Self-Control Strength constructed by Bertrams, Unger, and Dickhäuser (2011), measures the strength of self-control which is needed e.g., when restraining from attractive distraction while learning. The scale consists of 25 items (sample item: "I am motivated." responding scale: $1=$ I strongly disagree to $7=$ I strongly agree). Bertrams et al. (2011) proofed the scale to be reliable (Cronbach's alpha $\geq .93$ ) and valid.

Profile of Mood States. The adapted German version of the Profile of Mood States (POMS) published by Dalbert (1992) measures the state part of subjective wellbeing. The scale includes 19 items and the five subscales sorrow (sample item: sad), hopelessness (sample item: desperate), tiredness (sample item: exhausted), anger (sample item: angry), and positive mood (sample item: happy). Another subscale anger has been excluded as recommended by Dalbert (1992). The responding scale reached from $7=$ very strong to $1=$ not at all. Dalbert (1992) reported the scale as reliable (Cronbach's alpha between .83 and .94) and valid.

Current motivation. The current motivation was assessed by the questionnaire to assess current motivation in learning situations (QCM) by Rheinberg, Vollmeyer, and Burns (2001). The scale measures four motivational factors in achievement or learning situations. The scale consists of 18 items and includes the four subscales anxiety (sample item: "I am a bit embarrassed to fail here."), probability of success (sample item: "I probably will not manage the task."), interest (sample item: "I like such riddle and brain games."), challenge (sample item: "This task is a real challenge to me."). The responding scale is a 7 point Likert scale ( $1=I$ strongly disagree to $7=I$ strongly agree). Rheinberg et al. (2001) reported the scale to be reliable (Cronbach's alpha between .66 and .90) and valid. 


\section{Results}

We used SPSS 22.0 for all statistical analyses.

\subsection{Quality Criteria}

Before testing hypothesis the reliability of all included scales were tested. Most of the scales showed a Cronbach's alpha above .80, which can be evaluated as appropriate (Field, 2009).

Table 1. Descriptive data (mean (M) and standard deviation (SD)) and reliability (Cronbach's $\alpha$ ) for computer related attitudes $(N=32)$

\begin{tabular}{llll}
\hline & $M$ & $S D$ & $\alpha$ \\
\hline Learning \& working / positive & 4.08 & .54 & .79 \\
Learning \& working / negative & 2.13 & .76 & .87 \\
Entertainment \& communication / positive & 3.86 & .55 & .66 \\
Entertainment \& communication / negative & 2.08 & .45 & .20
\end{tabular}

The scales for computer related attitudes (Table 1) showed acceptable reliabilities for learning \& working. The subscale for entertainment \& communication/positive and entertainment \& communication/negative showed satisfactory values for Cronbach's alpha. Especially the reliability for entertainment \& communication/negative was too low (Cronbach's alpha $=.20$ ), so that the scale had to be excluded from further statistical analysis. Table 2 contains the reliability scores for all other scales. Results show that the measurement are mostly reliable and only the QCM subscales probability of success and challenge had reliabilities below .80 .

\subsection{Development of Computer Anxiety and Self-regulated Learning}

Mean and standard deviation of computer-anxiety and self-regulated learning scales for all three points of measurement are presented in Table 2. Computer-anxiety as part of external variables decreased over the course. Self-regulated learning as a measure for actual system use is operationalized into three subscales. The Momentarily Available Self-control Strength and Mood (Profile of Mood State) decreased from the beginning to the middle of the semester and remained stable afterwards. The scale for Current Motivation is divided into four subscales which are described separately. Challenge increases from the beginning to the middle of the semester and decreases at the end - computer-anxiety shows the opposite pattern. Probability of success increases from the beginning to the middle of semester and remains stable afterwards. Interest rises from the beginning to the middle of the course and almost reverts to the initial value from the beginning of the course. 
Table 2. Descriptive data (mean (M) and standard deviation (SD)) and reliability (Cronbach's $\alpha$ ) for computer anxiety and self-regulated learning scales

\begin{tabular}{lllllll}
\hline Scale & Time 1 & & Time 2 & \multicolumn{3}{l}{ Time 3 } \\
\hline COMA & $M(S D)$ & $\alpha$ & $M(S D)$ & $\alpha$ & $M(S D)$ & $\alpha$ \\
\hline POMS & $2.50(1.08)$ & .90 & $1.81(.72)$ & .90 & $1.91(.85)$ & .91 \\
Sorrow & $3.32(1.02)$ & .93 & $3.65(1.15)$ & .95 & $3.63(1.27)$ & .95 \\
Hopelessness & $2.32(1.61)$ & .91 & $2.63(1.60)$ & .93 & $2.32(1.69)$ & .95 \\
Tiredness & $1.73(.94)$ & .80 & $2.14(1.28)$ & .87 & $2.09(1.54)$ & .89 \\
Positive mood & $4.05(1.54)$ & .88 & $4.47(1.58)$ & .91 & $4.43(1.78)$ & .96 \\
\hline QCM & $3.86(1.05)$ & .91 & $3.62(1.12)$ & .90 & $3.49(1.36)$ & .94 \\
Anxiety & & & & & & \\
Probability of success & $2.84(1.42)$ & .84 & $2.91(1.13)$ & .72 & $2.59(1.17)$ & .81 \\
Interest & $3.29(.54)$ & .67 & $3.54(.53)$ & .48 & $3.55(.54)$ & .62 \\
challenge & $3.34(1.33)$ & .84 & $3.48(1.30)$ & .85 & $3.37(1.36)$ & .90 \\
\hline MASCS & $4.06(1.23)$ & .72 & $4.18(1.30)$ & .83 & $3.73(.98)$ & .61 \\
\hline Interest in course content & $4.36(.92)$ & .91 & $3.96(.95)$ & .95 & $3.97(1.39)$ & .97 \\
\hline joy & $3.59(.98)$ & -- & -- & -- & -- & -- \\
usage & -- & -- & -- & -- & $3.63(.98)$ & -- \\
recommendation & -- & -- & -- & -- & $3.52(1.06)$ & -- \\
aim & -- & -- & -- & -- & $3.97(.97)$ & -- \\
future usage & -- & -- & -- & -- & $3.71(1.01)$ & -- \\
course content & -- & -- & -- & -- & $3.70(1.09)$ & -- \\
\hline
\end{tabular}

Note $:$ COMA = Computer anxiety; MASCS = Momentarily Available Self-Control Strength; POMS = Profile of Mood States; $Q C M=$ Questionnaire to assess current motivation in learning situations

Additionally, interest in the course content and further external variables (e.g., Using the electronic portfolio in OneNote was fun for me.) were collected only at the beginning and at the end of the course, respectively. Means and standard deviation for these variables are also shown in Table 2. All means are above the scale mean. Students rated the recommendation of the portfolio to other students the highest and repeated usage of the course materials the lowest.

The first hypothesis stated that computer-anxiety will decrease in an easy-to-use system as an electronic portfolio in OneNote over one semester. Therefore, the three points of measurement of computer-anxiety were compared by a one-way repeated measures ANOVA. Results showed that the means of computer-anxiety decreased significantly from the first time of measurement to the second $\left(F(1.22,37.95)=12.73, p<.001, \eta^{2}=.29\right)$. This means that students felt safer in handling the computer from the beginning to the middle of the course. So, the first hypothesis claiming that computer-anxiety will decrease while working on an electronic portfolio was supported for the first part of the course.

The second hypothesis claims that measures of self-regulated learning increase over one semester with an electronic portfolio. The three points of measurement were again compared by a one-way repeated measures ANOVA. The scale of Momentarily Available Self-Control Strength, the Profile of Mood States (POMS) scale and its subscales as well as the subscales anxiety, probability of success and interest of the Questionnaire to assess current motivation in learning situations (QCM) showed no significant differences over time. In contrast, the means of challenge as part of the Questionnaire to assess current motivation in learning situations (QCM) decreased significantly from the middle to the end of the semester $\left(F(2,62)=3.76, p<.01, \eta_{\mathrm{p}}^{2}=.11\right)$. This means that students felt less challenged at the end of the course compared to the middle of the semester with the task to create an electronic portfolio with OneNote. 
Therefore, hypothesis two which states that measures of self-regulated learning increase across one semester can only be supported for challenge as part of the motivation for self-regulated learning.

\subsection{Connection to Computer related Attitudes}

Computer related attitudes were only measured once. Means and standard deviations are presented in Table 1 for each dimension. Students rated the computer as a positive tool for learning working the highest and the computer as a negative tool for entertainment and communication the lowest. Please note that all four dimensions of the computer related attitudes were rated separately by the participants.

\subsection{Connection between Computer related Attitudes and Computer-Anxiety}

Hypotheses three and four state a negative correlation between positive valences of computer related attitudes and computer-anxiety and positive correlation for negative valences and computer-anxiety. Results showed only one positive correlation between the positive valence (computer as a useful tool for learning and working) and computer-anxiety in the middle of the course, see Table 3 . This means that the more students thought that the computer was a useful tool for working and learning (positive valence) in the middle of the course the less computer-anxiety they reported, which supports hypothesis three partly.

Negative correlation between computer-anxiety and the negative valence could be found in learning and working in the middle and at the end of the course, see Table 3. This means the less useful students rated the computer for learning and working the more computer-anxiety they reported. Therefore hypothesis four is supported by the data.

\subsection{Connection of Computer related Attitudes with External Variables and Self-regulated Learning}

The first research question asks for correlations between computer related attitudes and external variables. Therefore, a Pearson correlation was calculated (see Table 3). The less useful the students rated the computer for working and learning (negative valence) the less joy they expressed about working with an electronic portfolio in OneNote, and said they would not recommend it to other students and did not want to work with the tool again in future courses.

For the second research question the correlation between computer-related attitudes and self-regulated learning as actual system use was investigated. Again, a correlation was calculated (see Table 3). The attitude that the computer is a useful tool for learning and working (positive valence) correlated positively challenge (QCM) in the beginning and end of the course as well as positive mood (POMS) and interest (QCM) at the end of the course. Students who viewed the computer with a negative valence for learning and working had a tendency to report higher levels of anxiety (QCM) in the beginning of the course, and more hopelessness (POMS) both in the beginning and in the middle of the course. A stronger negative view of computers was correlated with low measures in positive mood (POMS) in the beginning and in the end of the course and interest (QCM) at the end of the course. This means, the better students evaluated a computer for learning and working, the more challenge, interest and better mood they reported. In contrast, when students thought that a computer was not useful for working and learning, they reported more anxiety and hopelessness as well as less interest and less positive mood.

The attitude that a computer is a useful tool for entertainment and communication (positive valence) correlated positively with the POMS scale and its subscales sorrow, hopelessness and tiredness in the beginning of the course as well as sorrow in the middle of the semester. This means, when students tended to think that a computer was good for entertainment and communication they were likely to also report bad mood and stronger feelings of sorrow, hopelessness and tiredness, especially in the beginning of the course. Negative correlations were also found for the Momentarily Available Self-Control Strength scale at all three point of measurement, which means that the stronger students evaluated a computer for entertainment and communication the lower was the measure of self-control that they had indicated. 
Table 3. Correlation of computer related attitudes (learning and working; entertainment and communication) with computer-anxiety, self-regulated learning and external variables

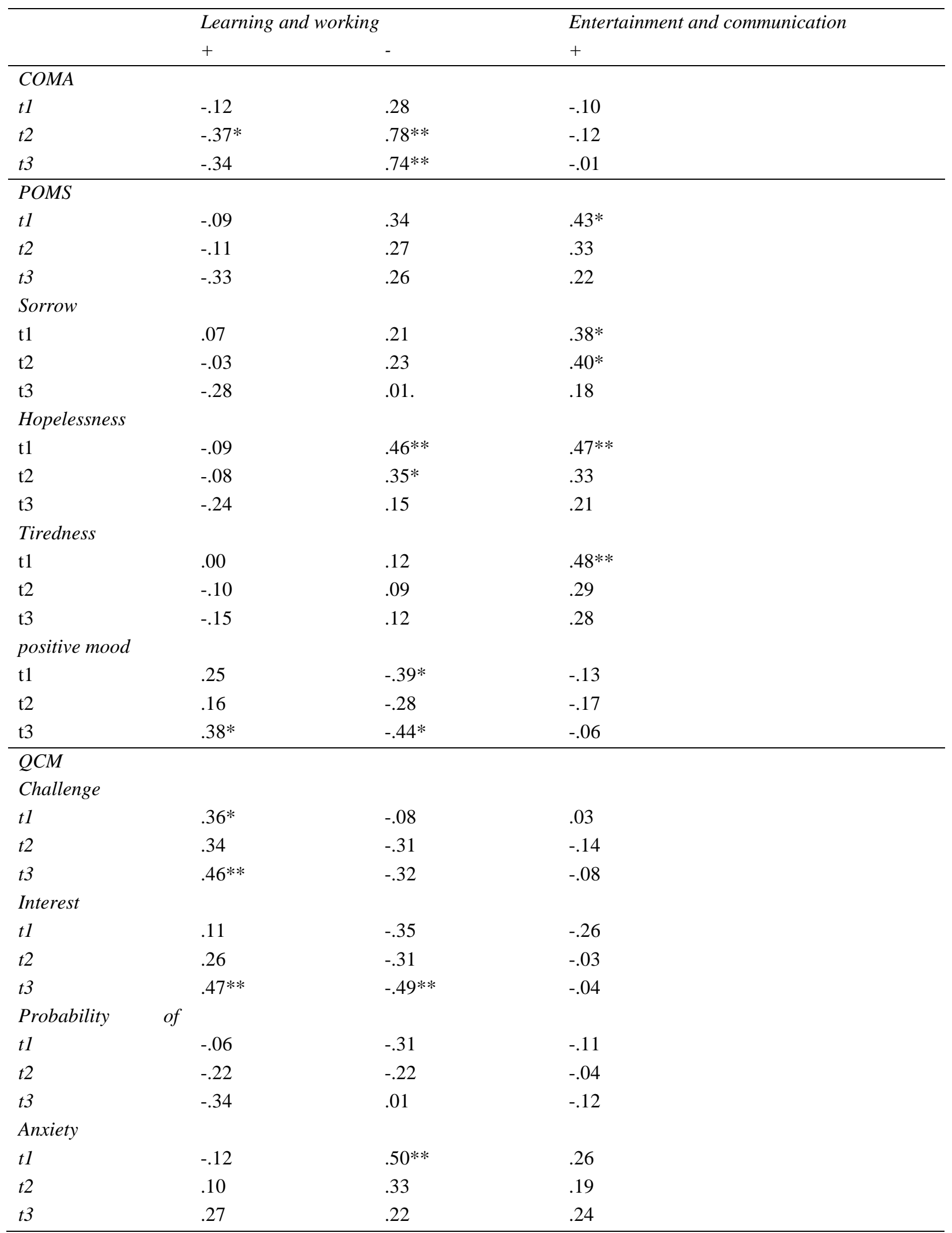




\begin{tabular}{llll}
\hline MASCS & & & \\
$t 1$ & .07 & -.26 & $-.47^{* *}$ \\
$t 2$ & .05 & -.28 & $-.49^{* *}$ \\
$t 3$ & .17 & -.18 & $-.38^{*}$ \\
\hline Interest & -.01 & -.01 & -.12 \\
\hline Joy & .16 & $-.36^{*}$ & -.06 \\
Usage & .23 & -.32 & .04 \\
Recommendation & -.01 & $-.36^{*}$ & -.10 \\
Aim & -.18 & -.24 & -.06 \\
future usage & .10 & $-.38^{*}$ & -.11 \\
course content & -.10 & -.21 & -.31
\end{tabular}

Note $:$ COMA = Computer anxiety; MASCS = Momentarily Available Self-Control Strength; POMS = Profile of Mood States; $Q C M=$ Questionnaire to assess current motivation in learning situations; $t 1=$ beginning of the course; $t 2=$ middle of the course; $t 3=$ end of the course $; * p<.05 ; * *<<.01$

\section{Discussion}

The aim of this study was to contribute to a better understanding of challenges and factors which influence learning efficiency with electronic portfolios. How can technical problems of electronic portfolios be minimized and overcome? How can the objective of the learning environment still focus on the content and how can the process of learning remain clearly in the focus of the activities? To address these issues, we decided to use an electronic portfolio in Microsoft OneNote, which contains features and functions that students are familiar with and caters beginners and advanced users.

To research the learning process of the students with the electronic portfolio in OneNote we first investigated the computer-anxiety, which is hypothesized to decrease over one semester. Results showed substantial decrease from the beginning to the middle of the course. In the second part of the semester computer-anxiety remained constantly. These findings also fit to previous results from Venkatesh and Bala (2008) as well as Richter et al. (2010), who found lower computer-anxiety coming with use of the computer over time. So, it is possible that students' computer-anxiety could be reduced, because they used the program every week and could get help at any time from the teacher, thus gaining confidence and skills.

The second hypothesis assumed an increase in self-regulated learning when students worked with an electronic portfolio over one semester. To operationalize self-regulated learning self-control, mood and motivation were measured. Apart from a decrease in challenge as part of motivation, self-control, mood and motivation remained stable over the course. These results only partly correspond to the findings of Alexiou and Paraskeva (2013), who hypothesized an increase in self-regulated learning. Differences of the results can be explained by varying instruments, which were administered to measure self-regulation and settings (working on an electronic portfolio in class with prepared tasks vs. working outside class with less guidelines).

Hypothesis three and four examined the relation between computer-anxiety and computer related attitudes. Results support the fourth hypothesis, which states a positive connection between computer-anxiety and negative valence of computer related attitudes. These correlations were found in the middle and the end of the semester for both parts of computer usage - for working and learning as well as for entertainment and communication. In contrast, a negative connection between computer anxiety and computer-related-attitude, were only found in the middle of the course for computer use for learning and working. These correlations match to the findings by Richter et al. (2000). According to this study, the positive correlation between computer anxiety and computer related attitudes was more explicit than the negative correlation. Furthermore, the positive correlations appeared only from the middle of the course on, not right from the beginning. The entire computer-based learning scenario, including the actual computer-use during class time, might have been too unfamiliar and intimidating at first; so it is reasonable to assume that personal experience is needed to make an informed assessment.

New in this study were the last two research questions that aim to further connections relating to computer related attitudes. According to the TAM variables were organized by external variables and actual system use in form of self-regulated learning. External variables influence technology acceptance of e.g. working with an electronic portfolio in OneNote. Results for external variables showed that if students did not find the computer as useful for 
learning and working, they had not enjoyed working on the electronic portfolio in OneNote, would not recommend the electronic portfolio to other students, and did not believe that they would use it someday in the future.

More correlations could be found between computer related attitudes and the actual system use, which was measured in the beginning, in the middle and at the end of the semester operationalized as self-regulated learning. The more students reported the computer as useful for learning and working, the more positive their mood was, the more they felt challenged and the higher their interest was. In contrast to this, when they believed that the computer was not useful for learning and working, they felt more hopeless, had less positive mood, less interest and more anxiety. Since correlation does not imply causation, it would be interesting to investigate if attitudes can be influenced from both directions.

When students thought that the computers are useful for entertainment and communication, they tended to express more sorrow, hopelessness and tiredness, on the one hand, and less self-control, on the other hand. Maybe because entertainment and communication via were not part of the course. Students might perceive the computer as an easily accessible device, which lends itself to effortless usage; when they have a habit of viewing computers as a means of entertainment, they might tend to avoid the association of computers with effortful learning and studying.

Limitations of the present study are that only a small group of students participated in the survey, and only correlations between computer related attitudes and further variables could be calculated, which restricts the explanatory power of the study. Larger sample sizes would allow for regression analyses which would be more powerful. Furthermore no control group was realized. To investigate our research questions, a control group was not really needed, because the focus of this study was on the development of self-regulation and computer anxiety while working with an electronic portfolio implemented in OneNote and the connection to computer related attitudes and not on course achievement. In the long run, however, knowledge and skill acquisition will be of interest, too. Another limitation is that the electronic portfolio had a strong structure and offered only limited options for personal adjustments. This decision was based on the fact that many students worked on a portfolio for the first time and very likely needed some structure and advice to complete the electronic portfolio during the course time. It is certainly within the range of OneNote to allow portfolio users more autonomy in terms of how to structure and to develop the electronic portfolio.

In further research, the OneNote electronic portfolio can be compared to other electronic portfolio systems to research strengths and weaknesses of the specific program. Additionally, it would be interesting to research if the computer related attitudes change especially for the facet "the computer is a useful tool for learning and working" after using the computer targeted for this purpose. According to the Technology Acceptance Model it would be helpful to adapt the model to technology use in higher education and develop appropriate scales, e.g., measuring for external variables, such as familiarity with the software and the learning content.

As a practical implication, we could demonstrate that it is possible to use OneNote as an easy-to-use-system for creating an electronic portfolio. This is supported by the stable measures of self-regulation over time. This study confirms the assumption that computer anxiety can be reduced by exposing learners to a computer assisted learning environment. It is, in a broad sense, a learning-by-doing- approach,which facilitates skill acquisition and growth in self-confidence to use technology for learning. Furthermore, the aim of the electronic portfolio was explained several times during the course and students received group-feedback to their work regularly. Students knew that the instructor read their electronic portfolios after the class session each week.

This study also showed correlations between the computer-related attitudes and self-regulation as well as computer-anxiety and external variables. This suggests that computer related attitudes might influence the computer handling and the feeling of computer-anxiety. We learned two things about building learning environments: On the one hand, pre-service teachers' computer-related attitudes need to be taken into account when designing courses which use electronic portfolios; and, on the other hand, the development of computer related attitudes can be affected by positive and meaningful computer applications in the field of learning. Prospective teachers are facing the challenge to define their attitude towards the use of technology in their teaching. They should, ideally, be able to make an informed decision about how to use digital devices in their classrooms. Therefore, we argue that the competence to critically reflect on the teaching value of computers is an indispensable aspect of teacher training. As we know from Levin (2015) teacher beliefs and attitudes influence their lesson planning and teaching behavior - in this case also the computer usage in class. A large part of pre-service teachers in Germany have never used the computer in a meaningful way and on a regular basis in their own schooldays because of the technical infrastructure in German schools (Bos et al., 2014) and even fewer have ever created an electronic portfolio. Therefore it is an ongoing challenge in teacher education programs to facilitate positive learning opportunities with computers in 
different courses and to enable teachers to assess the pro and cons of technology in the classroom (Ertmer, Ottenbreit-Leftwich, \& Tondeur, 2015).

\section{Conclusion}

In sum, this study contributes to the research of electronic portfolios and their usage in higher education courses. It emphasizes the role of computer-related attitudes as both a prerequisite and a goal of instruction, and the interplay between technology acceptance and complex applications, such as the electronic portfolios, and underlines the importance of fostering comprehension computer-assisted learning environments in teachers training.

\section{Notes}

This research did not receive any specific grant from funding agencies in the public, commercial, or not-for-profit sectors.

\section{References}

Ajzen, I., \& Fishbein, M. (1980). Understanding attitudes and predicting social behavior. Englewood Cliffs, NJ: Prentice-Hall.

Aldunate, R., \& Nussbaum, M. (2013). Teacher adoption of technology. Computers in Human Behavior, 29, 519-524. https://doi.org/10.1016/j.chb.2012.10.017

Alexiou, A., \& Paraskeva, F. (2010). Enhancing self-regulated learning skills through the implementation of an e-portfolio tool. Procedia - Social and Behavioral Sciences, 2, 3048-3054. https://doi.org/10.1016/j.sbspro.2010.03.463

Alexiou, A., \& Paraskeva, F. (Eds.). (2013). Exploiting Motivation and Self-efficacy through the Implementation of a Self-Regulated Oriented ePortfolio. Paper presented at The International Conference on E-Learning in the Workplace, NY, USA, June 12th-14th, 2013, Retrieved 10 February 2015, from http://www.icelw.org/program/ICELW\%202013\%20Proceedings/ICELW2013/papers/Alexiou_Paraskeva.pdf.

Bertrams, A., Unger, A., \& Dickhäuser, O. (2011). Momentan verfügbare -Selbstkontrollkraft - Vorstellung eines Messinstruments und erste Befunde aus pädagogisch--psychologischen Kontexten [Momentarily Available Self-Control Strength - Introduction of a Measure and First Findings from Educational-Psychological Contexts]. Zeitschrift für Pädagogische Psychologie, 25, 185-196. https://doi.org/10.1024/1010-0652/a000042

Bos, W., Eickelmann, B., Gerick, J., Goldhammer, F., Schaumburg, H., Schippert, K.,. . W Wendt, H. (Eds.). (2014). ICILS 2013: Computer- und informationsbezogene Kompetenzen von Schülerinnen und Schülern in der 8. Jahrgangsstufe im internationalen Vergleich [International survey of computer and information literacy of $8^{\text {th }}$ grade students]. Münster: Waxmann. Retrieved from select.com/portal/media/view/54f81eba-62c8-40ff-88f8-71e0b0dd2d03

Cai, Z., Fan, Xitao, \& Du, J. (2017). Gender and attitudes toward technology use: A meta analysis. Computers \& Education, 105, 1-13. https://doi.org/10.1016/j.compedu.2016.11.003

Cambridge, D. (2008). Audience, integrity, and the living document: EFolio Minnesota and lifelong and lifewide learning with ePortfolios. Computers \& Education, 51, 1227-1246. https://doi.org/10.1016/j.compedu.2007.11.010

Celik, V., \& Yesilyurt, E. (2013). Attitudes to technology, perceived computer self-efficacy and computer anxiety as predictors of computer supported education. Computers \& Education, 60, 148-158. https://doi.org/10.1016/j.compedu.2012.06.008

Cheng, G., \& Chau, J. (2013). Exploring the relationship between students' self-regulated learning ability and their ePortfolio achievement. The Internet and Higher Education, 17, 9-15. https://doi.org/10.1016/j.iheduc.2012.09.005

Dalbert, C. (1992). Subjektives Wohlbefinden junger Erwachsener: Theoretische und empirische Analysen der Struktur und Stabilität [Subjective well-being of young adults: Theoretical and empirical analyses of structure and stability]. Zeitschrift für Differentielle und Diagnostische Psychologie, 13, 207-220. Retrieved from http://wcms.uzi.uni-halle.de/download.php?down=20426\&elem=2495937

Darling-Hammond, L., \& Snyder, J. (2000). Authentic assessment of teaching in context. Teaching and Teacher Education, 16, 523-545. https://doi.org/10.1016/S0742-051X(00)00015-9 
Davis, F. D., Bagozzi, R. P., \& Warshaw, P. R. (1989). User Acceptance of Computer Technology: A Comparison of Two Theoretical Models. Management Science, 35, 982-1003. https://doi.org/10.1287/mnsc.35.8.982

Driessen, E. W., Muijtjens, A. M. M., van Tartwijk, J., \& van der Vleuten, C. P. M. (2007). Web- or paper-based portfolios: is there a difference? Medical Education, 41, 1067-1073. https://doi.org/10.1111/j.1365-2923.2007.02859.x

Erice, D., \& Ertas, A. (2011). The impact of e-portfolio on foreign language writing skills. Ankara Universitesi Egitim Bilimleri Fakultesi Dergisi, 73-94. https://doi.org/10.1501/Egifak_0000001225

Ertmer, P. A., Ottenbreit-Leftwich, A. T., \& Tondeur, J. (2015). Teachers' beliefs and use of technology to support 21st-century teaching and learning. In H. Fives \& M. G. Gill (Eds.), Educational Psychology Handbook. International handbook of research on teachers' beliefs (pp. 403-418). New York, NY: Taylor \& Francis.

Field, A. (2009). Discovering statistics using SPSS: (and sex and drugs and rock ' $n$ ' roll) (3rd ed.). Los Angeles: Sage Publications.

Hoy, A. W., \& Schönpflug, U. (2008). Pädagogische Psychologie [Educational Psychology] (10., bearb. Aufl. / bearb. und übers. von Ute Schönpflug). PS-Psychologie Always learning. München: Pearson Studium.

Imhof, M., \& Picard, C. (2009). Views on using portfolio in teacher education. Teaching and Teacher Education, 25, 149-154. https://doi.org/10.1016/j.tate.2008.08.001

Kimball, M. (2005). Database e-portfolio systems: A critical appraisal. Computers and Composition, 22, 434-458. https://doi.org/10.1016/j.compcom.2005.08.003

Levin, B. B. (2015). The development of teachers' beliefs. In H. Fives \& M. G. Gill (Eds.), Educational Psychology Handbook. International handbook of research on teachers beliefs (pp. 48-65). New York, NY: Taylor \& Francis.

Lynch, L. L., \& Purnawarman, P. (2004). Electronic portfolio assessments in U.S. educational and instructional technology programs: Are they supporting teacher education? TechTrends, 48, 50-56. https://doi.org/10.1007/BF02784865

Mansvelder-Longayroux, D. D., Beijaard, D., \& Verloop, N. (2007). The portfolio as a tool for stimulating reflection by student teachers. Teaching and Teacher Education, 23, 47-62. https://doi.org/10.1016/j.tate.2006.04.033

Moran, M., Hawkes, M., \& El Gayar, O. (2010). Tablet personal computer integration in higher education: Applying the unified Theory of Acceptance and Use Technology Model to understand supporting factors. Journal of Educational Computing Research, 42, 79-101. https://doi.org/10.2190/EC.42.1.d

Mueller, P. A., \& Oppenheimer, D. M. (2014). The pen is mightier than the keyboard: Advantages of longhand over laptop note taking. Psychological Science, 25, 1159-1168. https://doi.org/10.1177/0956797614524581

Reimer, Y. J., Brimhall, E., Cao, C., \& O'Reilly, K. (2009). Empirical user studies inform the design of an e-notetaking and information assimilation system for students in higher education. Computers \& Education, 52, 893-913. https://doi.org/10.1016/j.compedu.2008.12.013

Rheinberg, F., Vollmeyer, R., \& Burns, B. D. (2001). FAM: Ein Fragebogen zur Erfassung aktueller Motivation in Lern- und Leistungssituationen [QCM: A questionnaire to assess current motivation in learning situations]. Diagnostica, 2, 57-66. https://doi.org/10.1026//0012-1924.47.2.57

Richter, T., Naumann, J., \& Groeben, N. (2000). Attitudes toward the computer: Construct validation of an instrument with scales differentiated by content. Computers in Human Behavior, 16, 473-491. https://doi.org/10.1016/S0747-5632(00)00025-X

Richter, T., Naumann, J., \& Horz, H. (2010). Eine revidierte Fassung des Inventars zur Computerbildung (INCOBI-R) [A revised version of the Computer Literacy Inventory]. Zeitschrift für Pädagogische Psychologie, 24, 23-37. https://doi.org/10.1024/1010-0652/a000002

Rijdt, C. de, Tiquet, E., Dochy, F., \& Devolder, M. (2006). Teaching portfolios in higher education and their effects: An explorative study. Teaching and Teacher Education, 22, 1084-1093. https://doi.org/10.1016/j.tate.2006.07.002

Schmitz, B., \& Wiese, B. S. (1999). Eine Prozeßstudie selbstregulierten Lernverhaltens im Kontext aktueller affektiver und motivationaler Faktoren [A process study of self-regulated learning behavior in the context of 
motivational and emotional states]. Zeitschrift für Entwicklungspsychologie und Pädagogische Psychologie, 31, 157-170. https://doi.org/10.1026//0049-8637.31.4.157

Shapka, J. D., \& Ferrari, M. (2003). Computer-related attitudes and actions of teacher candidates. Computers in Human Behavior, 19, 319-334. https://doi.org/10.1016/S0747-5632(02)00059-6

Teo, T., Lee, C. B., \& Chai, C. S. (2008). Understanding pre-service teachers' computer attitudes: Applying and extending the technology acceptance model. Journal of Computer Assisted Learning, 24, 128-143. https://doi.org/10.1111/j.1365-2729.2007.00247.x

Venkatesh, V., \& Bala, H. (2008). Technology Acceptance Model 3 and a research agenda on interventions. Decision Sciences, 39, 273-315. https://doi.org/10.1111/j.1540-5915.2008.00192.x

Venkatesh, V., \& Davis, F. D. (2000). A theoretical extension of the Technology Acceptance Model: Four longitudinal field studies. Management Science, 46, 186-204. https://doi.org/10.1287/mnsc.46.2.186.11926

Wade, R. C., \& Yarbrough, D. B. (1996). Portfolios: A tool for reflective thinking in teacher education? Teaching and Teacher Education, 12, 63-79. https://doi.org/10.1016/0742-051X(95)00022-C

Zeichner, K., \& Wray, S. (2001). The teaching portfolio in US teacher education programs: What we know and what we need to know. Teaching and Teacher Education, 17, 613-621. https://doi.org/10.1016/S0742-051X(01)00017-8

Zimmerman, B. J. (2002). Becoming a self-regulated learner An overview. Theory into practice: TIP, 41, 64-70. https://doi.org/10.1207/s15430421tip4102_2 